\title{
Selectivity Enhancement to the Exclusive Formation of Ethyltoluenes and Hydrogen During Dehydroalkylation of Toluene with Ethane
}

Seyed Alireza Sadat Rezai · Yvonne Traa

Published online: 17 March 2009

(C) Springer Science+Business Media, LLC 2009

Erratum to: Catal Lett (2008) 122(1-2): 91-97 DOI 10.1007/s10562-007-9348-6

The author listing of the paper, Seyed Alireza, Sadat Rezai and Yvonne Traa, is incorrect. The two authors of this paper are Seyed Alireza Sadat Rezai and Yvonne Traa. We apologize for the error.

The online version of the original article can be found under doi:10.1007/s10562-007-9348-6.

S. Alireza Sadat Rezai · Y. Traa $(\bowtie)$

Institute of Chemical Technology, University of Stuttgart,

70550 Stuttgart, Germany

e-mail: yvonne.traa@itc.uni-stuttgart.de 